1. MBBS, FCPS

Assistant Professor of O \& G Independent Medical College, Faisalabad.

2. MBBS, FCPS

Assistant Professor of O \& G Independent Medical College, Faisalabad.

3. MBBS, FCPS

Assistant Professor of O \& $G$ Independent Medical College, Faisalabad.

Correspondence Address:

Dr. Nadia Awais

Assistant Professor of O \& G

175-Jinnah Colony Faisalabad.

naadiasharif@hotmail.com

Article received on:

15/06/2016

Accepted for publication: 07/09/2016

Received after proof reading: 07/10/2016

\title{
PREGNANCY INDUCED HYPERTENSION; TO COMPARE EFFICACY OF METHYLDOPA AND LABETALOL IN MANAGEMENT naadiasharif@hotmail.com
}

Dr. Nadia Sharif', Dr. Irum Usman², Dr. Tasneem Azhar ${ }^{3}$

ABSTRACT...Introduction: The hypertensive Disorders of pregnancy are major contributors to maternal and perinatal morbidity and mortality. The aim of hypertensive therapy is to prevent complications associated with hypertensive disorders of pregnancy. Objective: To compare efficacy of methyldopa and labetalol in management of pregnancy induced hypertension. Study Design: Randomized control trial. Setting: Punjab medical college and affiliated hospitals Faisalabad. Methods: Patient were be randomly assigned to either group A or Group by lottery method. Each group included 157 patients. In group A: labetalol was started at 100 $\mathrm{mg}$ three or four times a day and increased up to $1200 \mathrm{mg}$ a day in divided doses. In group B: methyldopa was started at $250 \mathrm{mg}$ per day 3 to 4 divided doses and increased up to $500 \mathrm{mg}$ in 3 to 4 divided doses. Blood pressure was recorded by sphygmomanometer. Blood pressure was recorded after 48 hours and then weekly till term on outpatient basis. Results: The treatment of methyldopa in group I was proved to successful in lowering the mean blood pressure and maintaining mean blood pressure within normal limits in 142 of 155 patients. It can be said it was successful in $91.61 \%$ cases. $8.39 \%$ cases progressed to severe hypertension or eclampsia because methyldopa was unsuccessful to prevent progress of disease. Conclusion: It is concluded that antihypertensive therapy such as methyldopa and labetalol are successful in lowering blood pressure in patient with pregnancy induced hypertension.

Keywords: Pregnancy induced hypertension, methyldopa, and labetalol

Article Citation: SharifN,Pregnancy induced hypertension; To compare efficacy of methyldopa and labetalol in management. Professional Med J 2016;23(10):1187-1193. DOI: 10.17957/TPMJ/16.3489

\section{INTRODUCTION}

Pregnancy is a state which can induce hypertension in normotensive women. ${ }^{1}$ Hypertension is one of the most common complications of pregnancy. ${ }^{2}$ It complicates 12 to $22 \%$ of all pregnancies. ${ }^{3}$ The spectrum of severity of hypertensive disorders of pregnancy is from mild to moderate disease being fairly substantial. ${ }^{4}$ It is a major contributor to maternal, fetal and neonatal morbidity. ${ }^{5}$ Early detection and appropriate management of hypertensive disorders of pregnancy may improve the outcome of both mother and fetus. ${ }^{6}$

The mild to moderate hypertension is acceptably diagnosed in the context of systolic blood pressure of $140-190 \mathrm{~mm}$ of $\mathrm{Hg}$ and a diastolic blood pressure of $90-109 \mathrm{~mm}$ of $\mathrm{Hg}$. Severe hypertension is labelled when systolic blood pressure is $>160 \mathrm{~mm}$ of $\mathrm{Hg}$ and diastolic blood pressure $>110 \mathrm{~mm}$ of $\mathrm{Hg}^{7}$
The aim of antihypertensive therapy of pregnancy is lowering the Blood Pressure, while prolonging the course of pregnancy. The treatment of moderate hypertension in pregnancy is associated with a significantly reduction in severe hypertension. ${ }^{8}$

The agents suggested for management of hypertension in pregnancy include methyldopa, nifedipine and labetalol. ${ }^{9}$ Various agents are associated with different side effects. Labetalol is being used worldwide as an effective hypertensive agent for many decades. Labetalol has the advantage that it can be given initially by mouth and then if needed intravenously by bolus or infusion. It is an alpha and beta adrenoceptor blocker and a frontline antihypertensive agent. ${ }^{10}$ The other drug is methyldopa which is an extensively studied drug used for treatment of hypertension in pregnancy. 
It is a centrally acting alpha 2 adrenoceptor agonist. Methyldopa has been proven safe in long term follow-up of the delivered babies ${ }^{11}$. However studies have suggested superior benefits of labetalol $^{12}$. Both methyldopa and labetalol are easily available and are also cost effective.

The rationale of this study was to collect conclusive evidence in support of the effective drug in the treatment of pregnancy induced hypertension. It suse will reduce material and fetal complications of uncontrolled pregnancy induced hypertension. That is why this study is beneficial for both the patients and our department.

\section{OBJECTIVE}

To compare efficacy of methyldopa and labetalol in management of pregnancy induced hypertension.

Main outcome measures of the study were:

- Treatment of moderate hypertension by achieving diastolic blood pressure during pregnancy $<90 \mathrm{~mm}$ of $\mathrm{Hg}$

- Preventing patient from progressing to severe hypertension(severe hypertension is blood pressure $>170 / 110$ )

The drug was considered efficacious when it fulfilled above criteria.

\section{MATERIAL AND METHODS}

Study Design Randomised control trial

Setting Punjab medical college and affiliated hospitals , Faisalabad

\section{SUBJECT}

The sample size was calculated by with $95 \%$ confidence level.

$$
\mathrm{P} 1=20 \% \quad \mathrm{P} 2=10 \%
$$

The sample size $(n)=157$ patients in each group fulfilling the inclusion and exclusion criteria

\section{INCLUSION CRITERIA}

All women with blood pressure after $20^{\text {th }}$ week of gestation;

- Systolic $150-160 \mathrm{~mm}$ of $\mathrm{Hg}$
- Diastolic $100-110 \mathrm{~mm}$ of $\mathrm{Hg}$

Known hypertensive on basis of history and clinical examination

\section{EXCLUSION CRITERIA}

Following patients will be excluded from the study

- History of chronic / essential hypertension

- History of Diabetes mellitus

- History of cerbero vascular disease

- History of Chronic renal failure

- History of multiple pregnancy

- History of collagen disease

Exclusion will be on basis of history and examination

\section{METHODS}

All inclusive Patients of the study were recruited from outpatients department or in the labour ward with pregnancy induced hypertension where clinical assessment of the patient was performed regarding inclusion and exclusion criteria.

Patient were randomly assigned to either group A or Group by lottery method. Each group included 157 patients.

In group A: labetalol was usually started at $100 \mathrm{mg}$ three or four times a day and then was increased up to $1200 \mathrm{mg}$ a day in divided doses.

In group B: methyldopa was started at $250 \mathrm{mg}$ per day 3 to 4 divided doses and was increased up to $500 \mathrm{mg}$ in 3 to 4 divided doses.

Blood pressure was recorded by sphygmomanometer. Blood pressure was recorded after 48 hours and then weekly till term on outpatient basis. Data was collected through specifically designed proforma. Successful lowering of blood pressure in terms of achieving desired blood pressure 140/90 was recorded.

Risks like maternal hypotension, flushing, nausea, vomiting and benefits like significant reduction of blood pressure, prevention of severe hypertension, side effects, reduced chances of abruption, low cost and control of blood pressure were explained to the patient. 
The study was approved from the ethical committee.

\section{STATISTICAL DATA ANALYSIS}

Frequency and percentages of all categorical variables like efficacy of drug were recorded. Mean and standard deviation for all numerical variables was calculated including age gestational age, parity, gravidity, abortion, blood pressure at booking, 48 hrs, week 1,2,3,4 will be recorded. Chi-square test was used to compare blood pressure (normal, raised) at 48 hours, week $1,2,3,4$ in both treatment groups. P-Value $<0.05$ was be considered significant.

\section{RESULTS}

In this study two groups were formed to method described. Group I was of 157 patients. The mean age was 27.30 years with standard deviation of \pm 4.197. The mean gravidity was 3.0 with standard deviation of \pm 1.616. Mean parity was $1.59 \pm$ 0.607 . The mean gestational age was 33.56 weeks with standard deviation of \pm 2.450 as mentioned in table 1.

\begin{tabular}{|c|c|c|c|}
\hline VARIABLE & NUMBER & MEAN & $\begin{array}{c}\text { STANDARD } \\
\text { DEVIATION }\end{array}$ \\
\hline AGE (years) & 157 & 27.30 & \pm 4.197 \\
\hline G (gravidity) & 157 & 3.00 & \pm 1.616 \\
\hline P (parity) & 157 & 1.59 & \pm 1.549 \\
\hline A (abortion) & 157 & 0.39 & \pm 0.607 \\
\hline $\begin{array}{c}\text { Gestational age } \\
\text { (weeks) }\end{array}$ & 157 & 33.56 & \pm 2.450 \\
\hline $\begin{array}{c}\text { TABLE NO 1: EPIDEMIOLOGICAL VARIABLES } \\
\text { Group I (methyldopa) }\end{array}$ \\
\hline
\end{tabular}

The subjects of group I were given methyldopa according to the protocol and blood pressure was recorded at booking , 48 hours, 1 week , 2 weeks , 3 weeks and 4 weeks. All patients were followed on out patient basis. Two patient were lost to follow up. The mean blood pressure at booking was $155.30 / 104.58$, at 48 hours 140.32 / 93.06 , at $1^{\text {st }}$ week $134.76 / 90.99$, at $2^{\text {nd }}$ week $132.54 / 90.14$, at $3^{\text {rd }}$ week $131.26 / 89.55$ and at $4^{\text {th }}$ week $131.19 / 85.68$. This shows gradual reduction in blood pressure on antihypertensive therapy in form of methyldopa. (Table 2)

\begin{tabular}{|c|c|c|c|}
\hline BLOOD PRESSURE & NUMBER & MEAN & $\begin{array}{l}\text { STANDARD } \\
\text { DEVIATION }\end{array}$ \\
\hline Booking systolic BP & 157 & 155.30 & \pm 7.582 \\
\hline Booking diastolic BP & 157 & 104.58 & \pm 5.313 \\
\hline Systolic BP at $48 \mathrm{hrs}$ & 157 & 140.32 & \pm 10.82 \\
\hline Diastolic BP at $48 \mathrm{hrs}$ & 157 & 93.06 & \pm 5.822 \\
\hline Systolic BP at 1 week & 147 & 134.76 & \pm 8.467 \\
\hline Diastolic BP at 1 week & 147 & 90.99 & \pm 5.753 \\
\hline Systolic BP at 2 week & 138 & 132.54 & \pm 5.412 \\
\hline Diastolic BP at 2 week & 139 & 90.14 & \pm 3.944 \\
\hline Systolic BP at 3 week & 111 & 131.26 & \pm 6.341 \\
\hline Diastolic BP at 3 week & 110 & 89.55 & \pm 2.837 \\
\hline Systolic BP at 4 week & 84 & 131.19 & \pm 10.46 \\
\hline Diastolic BP at 4 week & 88 & 85.68 & \pm 19.06 \\
\hline \multicolumn{4}{|c|}{$\begin{array}{c}\text { TABLE NO 2: MEAN BLOOD PRESSURE } \\
\text { Group I (methyldopa) }\end{array}$} \\
\hline
\end{tabular}

The treatment of methyldopa in group I was proved to successful in lowering the mean blood pressure and maintaining mean blood pressure within normal limits in 142 of 155 patients. It can be said it was successful in $91.61 \%$ cases. $8.39 \%^{13}$ cases progressed to severe hypertension or eclampsia because methyldopa was unsuccessful to prevent progress of disease. (Graph 1)

Group II was of 157 patients. The mean age was 26.89 years with standard deviation \pm 4.82 . The mean gravidity was 3.03 with standard deviation \pm 1.64 . Mean parity was $1.62 \pm 0.61$. The mean gestational age was 33.57 weeks with standard deviation of \pm 2.43 as mentioned in Table 3 . 


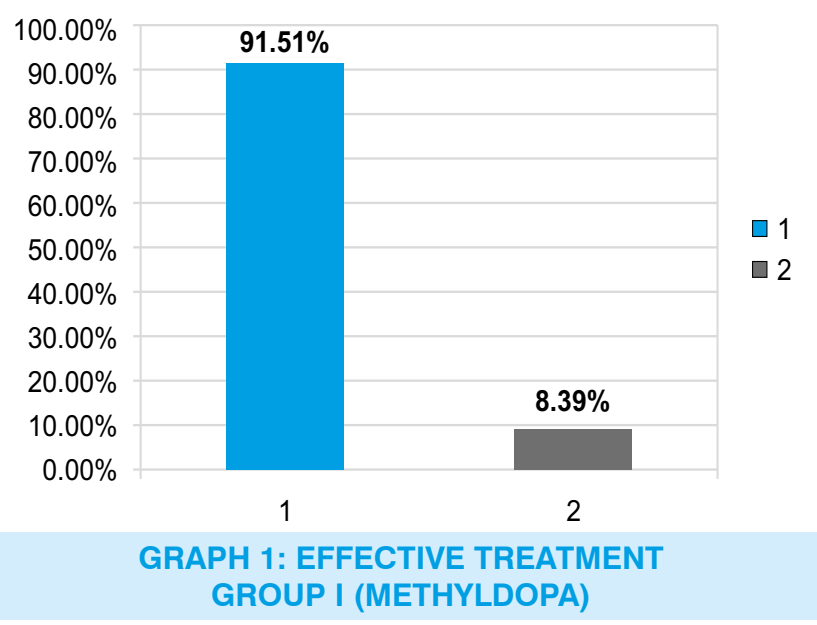

\begin{tabular}{|c|c|c|c|}
\hline VARIABLE & NUMBER & MEAN & $\begin{array}{c}\text { STANDARD } \\
\text { DEVIATION }\end{array}$ \\
\hline AGE (years ) & 156 & 26.89 & \pm 4.82 \\
\hline G (gravidity) & 156 & 3.03 & \pm 1.64 \\
\hline P(parity) & 156 & 1.62 & \pm 1.58 \\
\hline A ( abortion) & 156 & 0.38 & \pm .61 \\
\hline $\begin{array}{c}\text { Gestational age } \\
\text { ( weeks ) }\end{array}$ & 156 & 33.57 & \pm 2.43 \\
\hline \multicolumn{2}{|c|}{ TABLE NO 3: EPIDEMIOLOGICAL VARIABLES } \\
\multicolumn{4}{|c|}{ Group II (labetalol) } \\
\hline
\end{tabular}

The subjects of group II were given labetalol according to the protocol and blood pressure was recorded at booking , 48 hours , 1 week , 2 weeks , 3 weeks and 4 weeks. All patients were followed on out patient basis. Two patient were lost to follow up. The mean blood pressure at booking was 155.5/104.6, at 48 hours $140.6 / 93.24$, at $1^{\text {st }}$ week $135.3 / 93.24$, at $2^{\text {nd }}$ week $132.6 / 90.14$ , at $3^{\text {rd }}$ week $131.3 / 89.54$ and at $4^{\text {th }}$ week 131.4 / 85.44. This shows gradual reduction in blood pressure on antihypertensive therapy in form of methyldopa. (table 4)

The treatment of labetalol in group II was proved to successful in lowering the mean blood pressure and maintaining mean blood pressure within normal limits in 141 of 156 patients. It can be said it was successful in $90.38 \%$ cases. $9.62 \%{ }^{15}$ cases progressed to severe hypertension or eclampsia because methyldopa was unsuccessful to prevent progress of disease. (Graph 2)

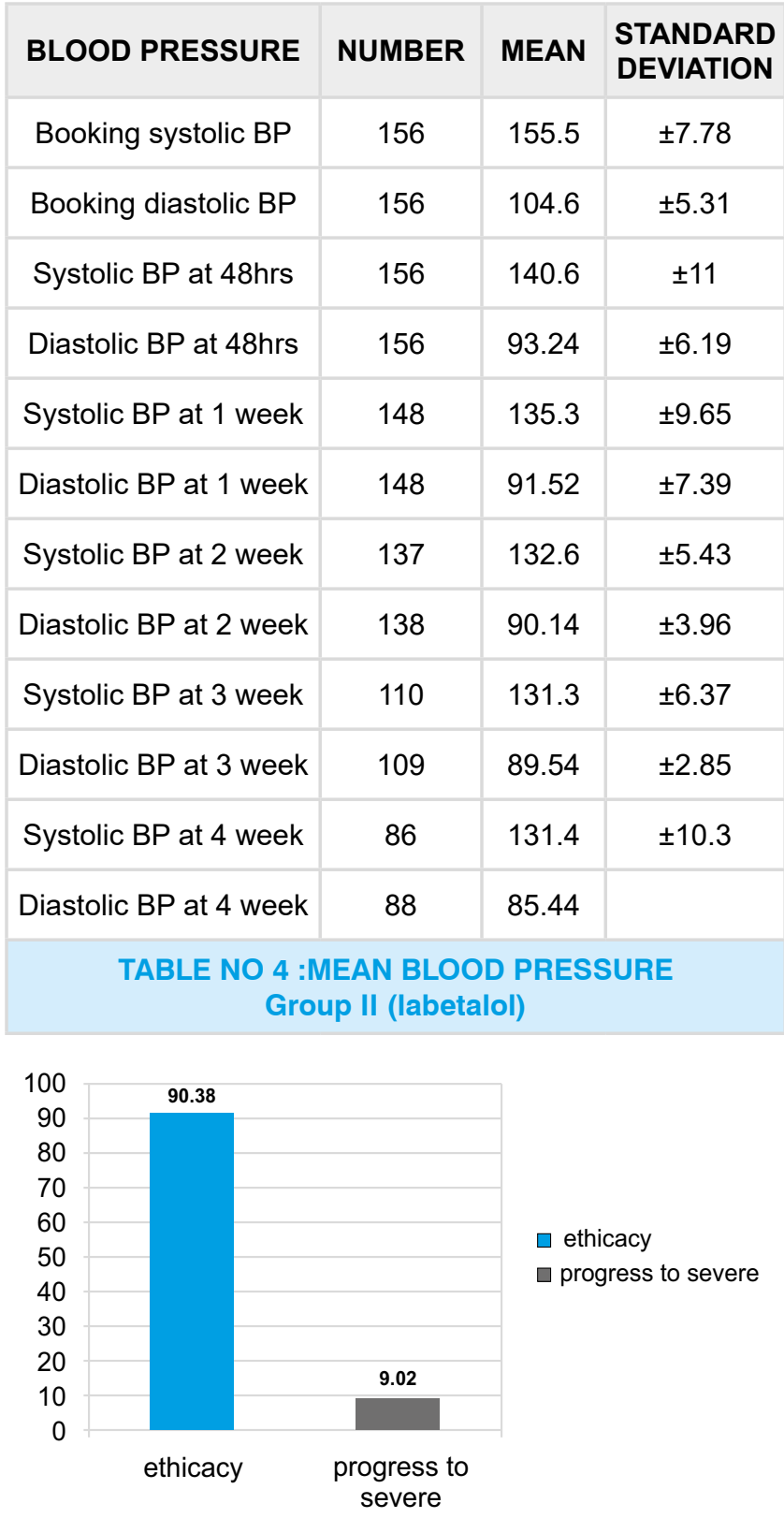

\section{GRAPH 2: EFFECTIVE TREATMENT}

Group II (labetalol)

\section{Statistical analysis}

We used the analysis of variance test to compare the groups. First we applied the ANOVA in SBP and second in DBP. We concluded that the there was no difference in methyldopa group $1 \& 2$ in SBP because the $p$-value is 0.64 (non-significant). Secondly used the anova in DBP the p-value is 0.61 (not significant) and conclude that the there is no difference in methyl dopa group $1 \& 2$. The overall result is non-significant. 


\section{DISCUSSION}

The importance of this study is evident from the magnitude and sheer impact of pregnancy induced hypertension. International studies state that approximately $6-10 \%$ of pregnant women suffer from pregnancy induced hypertension. $(1,2)$.local studies support these figure by showing that about $1 / 5^{\text {th }}$ of pregnancies suffer form of hypertension. ${ }^{3}$

This study suggests that pregnancy induced hypertension can be successfully treated with oral hypertensive agents such as methyldopa and labetalol. These both agents were compared in terms of efficacy and ability to prevent severe hypertension. This study shows that both agents, methyldopa and labetalol had efficacy of $91.61 \%$ and $90.38 \%$ in lowering blood pressure .There was no significant statistical significant in there efficacy as proven by Chi-square test with $\mathrm{P}>0.5$. These figures are supported by meta-analysis by Magee $L$ and Duley L. This meta-analysis of thirteen trials compared beta-blockers with methyldopa . Beta-blockers appear to be no more effective and probably equally as safe. It is unusual for women to change drugs due to side effects. ${ }^{4}$

The efficacy of labetalol in study by Mahmoud shows efficacy of labetalol in controlling blood pressure in $85 \%$ patients on this drug. ${ }^{6}$ In This study the efficacy of drug was determined when it achieved a safer target blood pressure which was comparable to the safe range of blood pressure 140 to $155 / 90$ to $105 \mathrm{~mm}$ of $\mathrm{Hg}$ mentioned in study by Podymow and August. ${ }^{5}$

In both groups of this study the mean blood pressure at booking was 155/104 which was comparable with study of Mahmoud, Bjornsson and Calder. ${ }^{6}$ In this study in both groups majority of cases were successfully treated and prevented from progressing to severe hypertension and eclampsia. In group 1, $8.39 \%$ progessed to severe hypertension and in group II $9.63 \%$ progressed. Study by mahmoud had $18.5 \%$ cases progressing to severe hypertension. ${ }^{7}$
In another meta-analysis, patients treated with labetalol was unsuccessful in $8 \%$ cases progressing to severe hypertension and in patients on methyldopa $10 \%$ cases progessed to severe hypertension which is almost similar to the findings of our study. ${ }^{8}$ Our study has results which are comparable by various national and international studies with almost similar results which is suggestive that both methyldopa and labetalol are successful antihypertensive agents used during pregnancy induced hypertension and have good safety profile. Both do not have significant difference in there efficacy and ability to prevent patient's progress to severe hypertension.

\section{CONCLUSION}

It is concluded that antihypertensive therapy such as methyldopa and labetalol are successful in lowering blood pressure in patient with pregnancy induced hypertension. This study shows that methyldopa and labetalol were successful in lowering blood pressure in $91.61 \%$ and $90.38 \%$ cases. In group I $8.39 \%$ cases progressed to severe hypertension and in group II $9.69 \%$ progressed to severe hypertension. The mean blood pressure reduction in group I (methyldopa) was $16.44 \%$ reduction in systolic blood pressure and $17.14 \%$ reduction in mean diastolic blood pressure. The mean blood pressure reduction in group II (labetalol) was $15.84 \%$ reduction in systolic blood pressure and $18.40 \%$ reduction in mean diastolic blood pressure.

The data was analysed and variables of both groups were subjected to chi-square test which concluded that there was no significant difference in the efficacy of both groups in terms of blood pressure control and preventing the disease to progress to severe hypertension.

Our conclusion is a null hypothesis which concludes that both drugs labetalol and methyldopa have proved to be efficient in preventing progress of disease and controlling pregnancy induced hypertension. No significant difference was found. Further studies are recomended to assess the safety profile of both 
drugs.

Copyright(C) 07 Sep, 2016.

\section{REFERENCES}

1. Akmal N, Gul e rana. Women with pregnancy induced hypertension; epidemiological differences between normotensive pregnant women. Professional Med J $2006 ; 13: 310-2$

2. Jehan Ara, jamal M, Sultan N. Perinatal outcome in pregnancy induced hypertensive mothers. Pak Armed Forces Med J 2004; 54 : 76-8

3. Walfisch A, Hallak M. Hypertension. In: James DK, Weiner CP, Gomik B (edi). High Risk Pregnancy: management options, $3^{\text {rd }}$ ed. Philadelphai: Saunders 2006 ; 772-97

4. Paruk F, Moodley J. Antihypertensive Thraphy for the management of mild to moderate hypertension? In: Stud J (edi): Progress in obstetrics and gynaecology. Vol 16. Edinburgh : Elsevier $2005 ; 23-5$

5. Magee LA, Von Dadelszen P, Chan S, Gafni A, Gruslin $A$, Halewa $M$, et al: The control of hypertension in pregnancys, Study pilot trail. BJOG $2007 ; 114: 770$, e13-20

6. Vigil D Garcila, Ruiz E, Lopez JC, Jaramillo IA, VegaMaleck JC, Pinzon J. Management of severe hypertension in post partum period with hydralazine or labetalol: A randomized clinical trail. Hypertens pregnancy $2007 ; 26(2)$ : 163-71

7. Paruk F, Moodley J. Antihypertensive Thraphy for the management of mild to moderate hypertension? In: Stud J (edi): Progress in obstetrics and gynaecology. Vol 16. Edinburgh: Elsevier $2005 ; 23-5$

8. Shennan A, Chronic Hypertension. In: luesly DM, Baker PN, editors. Obstetric and Gynaecology: an evidence base text for MRCOG. London: Arnold 2010; 45-8

9. Abalos E, Duley L, Stey DW, Henderson Smart DJ: Antihypertensive Drug therapy for mild to moderate hypertension during pregnancy Cochrane review, Cochrane library issue no. 3, Oxford update software 2001.

10. Chung PC, Ng YT, Hsieh IR, Yang MW, Li All. Labetalol reduces blood pressure instability during surgical resection of pheochromocytoma. J Fonnos Med issoc 2006 ; 150 : 189-91

11. Warren R, Arulkumaran S, Walker JW. Management of severe preeclampsia / eclempsia, chapter 24. Best practive in labour and delivery. $\mathrm{Pg} 262-272$.

12. Magee LA, Ornstein MD, VonDadelszen P. Forthnightly review: management of hypertension in pregnancy. Br Med J 1999 ; 318 : 1332-6

13. 108 Belfort MA, Anthony J, Buccimazza A, Davey DA. Hemodynamic changes associated with intravenous infusion of the calcium antagonist verapamil in the treatment of severe gestational proteinuric hypertension. Obstet Gynecol 1990;75:970-4.

14. 109 Pasker-de Jong P, Zielhuis G, Van Gelder M, Pellegrino A, Gabreels F, Eskes T. Antihypertensive treatment during pregnancy and functional development at primary school age in a historical cohort study. BJOG 2010;117:1080-1087.

15. 110 Khalil A, HarringtonK, Muttukrishna S, Jauniaux E. Effect of antihypertensive therapy with alpha methyldopa on uterine artery Doppler in pregnancies with hypertensive disorders; Ultrasound Obstet gynecol 2010;35:688-694.

16. 112 Aslam A, Talat W, Aslam A. PREGNANCY INDUCED HYPERTENSION: Antihypertensive therapy in a study using single Drug versus multiple drugs. Professional Med J Mar2007;1"4(1):30-3

17. 113 Magee L. Duley L, Oral beta-blockers mild to moderate hypertension during pregnancy. Cochrane Database of systemic reviews 2003. Issue 3. Art No: CD002863.DOI:10.1002/14651858.CD002863.

18. 114 Podymow T, August P. Update on the use of antihypertensive drugs in pregnancy. Hypertension. 2008;51:960-969.

19. 115 Mahmoud, Bjornsson S, Calder AA. Labetalol therapy in pregnancy induced hypertension: the effects on fetoplacental circulation and fetal outcome. European Journal of Obstetrics \& gynaecology and reporductive Biology. May 2005. http://www. sciencedirect.com.download on 10/01/2010.

20. 116 Magee LA, Duley L. Oral beta blockers fro mild to mederate hypertension during pregnancy. Cochrane Database Sys Rev 2003;(3):CD002863.PM.12917933.

\section{PREVIOUS RELATED STUDY}

Noreen Akmal, Gul-e-Raana WOMEN WITH PREGNANCY INDUCED HYPERTENSION; EPIDEMIOLOGICAL DIFFERENCES BETWEEN NORMOTENSIVE PREGNANT WOMEN (Original) Prof Med Jour 13(2) 310-312 Apr, May, Jun, 2006. 


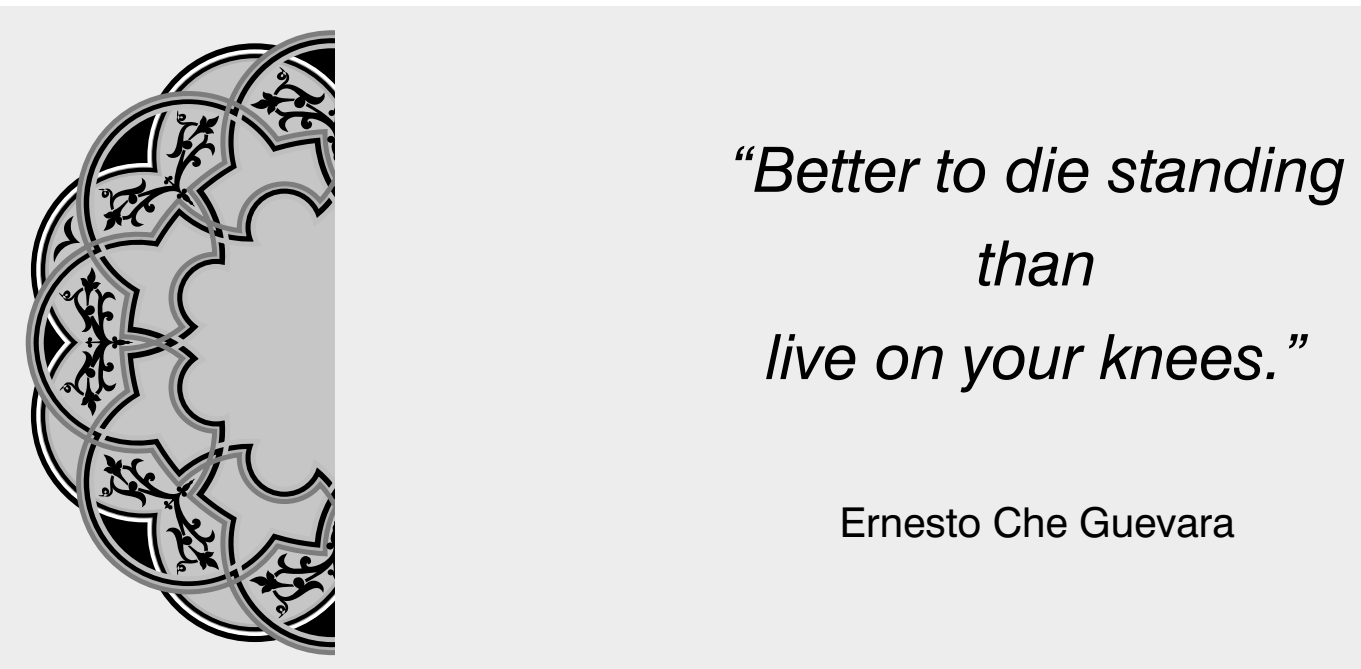

AUTHORSHIP AND CONTRIBUTION DECLARATION

\begin{tabular}{|c|l|l|l|}
\hline Sr. \# & \multicolumn{1}{|c|}{ Author-s Full Name } & \multicolumn{1}{|c|}{ Contribution to the paper } & Author=s Signature \\
\hline 1 & Naadia Sharif & Helped on Data Collection \\
\hline 2 & Dr. Irum Usman & \\
\hline 3 & Dr. Tasneem Azhar & \\
\hline
\end{tabular}

